\title{
Journey of Mesenchymal Stem Cells for Homing: Strategies to Enhance Efficacy and Safety of Stem Cell Therapy
}

\author{
Sung Keun Kang, Il Seob Shin, Myung Soon Ko, Jung Youn Jo, and Jeong Chan Ra
}

Stem Cell Research Center, RNL BIO, Gasan-Dong, Geumcheon-Gu, Seoul 153-768, Republic of Korea

Correspondence should be addressed to Jeong Chan Ra, jcra@rnl.co.kr

Received 3 February 2012; Revised 6 April 2012; Accepted 17 April 2012

Academic Editor: Reinhard Henschler

Copyright ( $) 2012$ Sung Keun Kang et al. This is an open access article distributed under the Creative Commons Attribution License, which permits unrestricted use, distribution, and reproduction in any medium, provided the original work is properly cited.

\begin{abstract}
Human mesenchymal stem cells (MSCs) communicate with other cells in the human body and appear to "home" to areas of injury in response to signals of cellular damage, known as homing signals. This review of the state of current research on homing of MSCs suggests that favorable cellular conditions and the in vivo environment facilitate and are required for the migration of MSCs to the site of insult or injury in vivo. We review the current understanding of MSC migration and discuss strategies for enhancing both the environmental and cellular conditions that give rise to effective homing of MSCs. This may allow MSCs to quickly find and migrate to injured tissues, where they may best exert clinical benefits resulting from improved homing and the presence of increased numbers of MSCs.
\end{abstract}

\section{Introduction}

The promise of regeneration is what has sparked an international effort to expand the field of stem cell research. In particular, the study of mesenchymal stem cells (MSCs) and their effects on cellular degenerative diseases is rapidly increasing. The role of MSCs in the modulation of the immune response, immune system activity, and the body's response to inflammation and disease has been widely studied for many years [1-5]. Multiple studies have demonstrated that cultured MSCs have the ability to differentiate into bone and cartilage $[6,7]$ as well as other cell types and tissues both in vitro and in vivo $[2,6,8]$. Among other researchers, Ankrum and Karp demonstrated that MSCs differentiate into osteocytes, adipocytes, neural cells, and vascular endothelial cells [2].

Recent research, however, has shown that the environment plays a crucial role in limiting or expanding the differentiation capacity of MSCs [9-13]. Lavasani et al. [13] demonstrated that muscle stem cells from young mice conferred significant lifespan and healthspan extension in progeroid mice, which have stem cells defective in proliferation and multilineage differentiation. Furthermore, microenvironmental changes regulate the potential of MSCs to differentiate into specific cell types [14-17], and this effect on differentiation seems to be characterized by a variety of factors not yet well understood, such as the length of telomeres of cells in the microenvironment $[10,18]$. While bone marrow MSCs (BMMSCs) were shown to have a decreased lifespan, rate of population doubling time [19], actual bone formation as patient age increased [14], adipose tissuederived MSCs (AdMSCs) do not appear to undergo the same senescence pattern as BMMSCs [10, 18]. Mirsaidi et al. [18] demonstrated that murine AdMSCs derived from senile osteoporotic SAMP6 mice showed maintenance of telomere length, telomerase activity, and osteogenic differentiation. In addition, Chen et al. [10] demonstrated that human AdMSCs from elderly (mean age: 71.4 years) and young (mean age: 36.4 years) donors showed similar increases in proliferation rate, osteogenic differentiation potential, and senescence marker patterns, while BMMSCs from the same cohorts showed reduced proliferation rate, decreased differentiation potential, and increased senescence. Ultimately, however, the relationship between MSCs and their environment is 
reciprocal. Just as the microenvironmental effects on MSCs can constrict their response to a bodily insult, MSCs can activate or deactivate immune system within the environment $[1,5]$. MSCs are sometimes referred to as "balancers" due to the extensive research linking the presence and activity of in vivo MSCs and homeostasis [20].

The notion of balance is somewhat circuitous; MSCs appear to both rely upon and cocreate a network that facilitates constant communication between normal and damaged cells in the body [20]. MSCs are dispatched by what might be metaphorically compared to a fire alarm, through a signaling system that has been extensively studied but remains not fully understood. In particular, the factors that trigger MSC responses and the tools required for MSCs to respond in a positive way to a particular insult to the body remain largely unknown [21-25]. To effectively fight the fires in our bodies, an adequate supply of MSCs with high potential are needed to, metaphorically, act as firefighters. Properly culture-expanded and engineered MSCs with enhanced homing capability can ensure removal of the damaged cells and increase the rate of regeneration when the balance is disrupted in the body. Furthermore, strategies to modulate the physiological barrier of blood vessels and the lung, the inflammatory microenvironment of the body, and the chemotactic signals from the damage site will enhance MSC homing. A variety of strategies have been suggested to enhance the homing of MSCs based on their well-known characteristics.

In this paper, we will review the current understanding of MSC migration and discuss strategies for enhancing their trafficking to injured tissues to improve the clinical benefits of MSC transplantation.

\section{Characterization and Phenotype of MSCs}

To explore the migration and homing of MSCs, first it is necessary to describe the differences among the types of MSCs and to identify the taxonomy of MSCs and the range of their environments and behaviors. MSCs are defined as multipotent cells with self-renewal capacity, capable of differentiating into a variety of cells [26]. Since the first isolation of MSCs from the bone marrow by Friedenstein and colleagues [27], MSCs have been derived from multiple tissues [2]. Since different methods have been employed to culture MSCs from multiple tissues, to assess their differentiation potential and to evaluate their capacity for self renewal, it is critical to set accepted criteria for defining MSCs. Given the lack of universally accepted criteria for defining MSCs, the Mesenchymal and Tissue Stem Cell Committee of the International Society for Cellular Therapy proposed a set of standards to define MSCs for both laboratory-based scientific investigations and preclinical studies [28]. These are: (1) plastic adherence ability; (2) lack of hematopoietic markers, such as CD45, CD34, CD14, CD11b, CD79 $\alpha$, CD19, and HLADR; (3) tripotential mesodermal differentiation potency into osteoblasts, chondroblasts, and adipocytes. Along with mesodermal differentiation capability, MSCs were shown to differentiate into cells of the ectodermal lineage such as neurons [29-31], keratocytes [32], and keratinocytes [33], but also into cells of the endodermal lineage such as hepatocytes $[34,35]$ and pancreatic $\beta$-cells [36]. Although the differentiation capability of MSCs into cells of the ectodermal and endodermal lineages has been demonstrated in previous studies, MSC differentiation to these lineage cells requires further investigation. Besides cellular differentiation, through an interaction with a series of signals from local tissue, engrafted MSCs can secrete diverse cytokines, possess trophic and immunomodulatory functions, and subsequently contribute to tissue repair and/or regeneration [2].

MSCs are found in various tissues and organs, including fat, periosteum, synovial membrane, synovial fluid, muscle, dermis, deciduous teeth, pericytes, trabecular bone, infrapatellar fat pad, articular cartilage, umbilical cord and cord blood [37, 38], and the placenta [39]. BMMSCs were first isolated and used in disease indications [40]. Aspirating bone marrow from patients is an invasive procedure [41] and yields only low numbers of cells (about $1-10$ cells per $1 \times 10^{5}$ cells or $0.0001-0.01 \%$ of all bone marrow nucleated cells), requiring longer and more complex in vitro cellular expansion procedures [42]. However, Ohgushi et al. [43] demonstrated that BMMSCs cultured from $3 \mathrm{~mL}$ of aspirated bone marrow obtained by noninvasive needle aspiration under local anesthesia showed therapeutic effects in treating osteoarthritis [43]. The therapeutic potential of BMMSCs was influenced by donor age, showed declining differentiation capacity, and reduced vitality in vitro with increasing donor age [44]. Adipose tissue is an attractive source of MSCs for stem cell therapy because it is easily obtainable in sufficient quantities by a minimally invasive procedure $[45,46]$. Furthermore, adipose tissue contains more MSCs than does the bone marrow (about 100,000 MSCs per gram of fat) [47], while differentiation and immunomodulatory potencies of AdMSCs are equivalent to those of BMMSCs [46]. Of interest, a comparative study on the differentiation capability between BMMSCs and AdMSCs was performed using cells from the same donor rat. Hayashi et al. clearly demonstrated an excellent osteogenic differentiation capability of BMMSCs compared with AdMSCs derived from the same donor rat [48].

\section{Distribution of MSCs after Systemic Infusion}

The distribution and migratory properties of systemically injected MSCs is helpful in determining the metrics of homing efficiency. After intravenous delivery, MSCs are found at low or very low frequencies in most target organs, as shown by fluorescent protein labeling [49-52], transduction of MSCs with reporter genes [53, 54], detection of human genes in animal recipients [55-58], sex-linked chromosome gene for sex mismatch $[59,60]$, histology $[51,61]$, immunohistochemistry $[53,54,56,57]$, real-time PCR [49, 59], and fluorescent in situ hybridization [59, 60]. For instance, in baboons, by detecting transplanted cell-specific DNA, Devine et al. [49] demonstrated a high number of transplanted cells observed in gastrointestinal tissues and a relatively high number of cells also observed in the kidney, lung, liver, thymus, and skin. The levels of engraftment in 
these tissues were estimated, ranging from $0.1 \%$ to $2.7 \%$ of the administered cells. In noninjury models, by detecting enhanced green fluorescent protein (GFP)-transfected murine MSC, Deak et al. [52] demonstrated that the most frequently GFP-positive organs were the lungs, liver, kidney, skin, and gut among investigated tissues $24 \mathrm{~h}$ after MSC transplantation. However, the aforementioned methods are invasive and static, meaning the cells are not dynamically tracked. To overcome these problems, non- or minimallyinvasive and efficient real-time imaging techniques are required. The development of noninvasive techniques such as magnetic resonance imaging (MRI) on superparamagnetic iron oxide (SPIO) nanoparticle-labeled MSCs [62-64], combined single-photon emission CT (SPECT)/CT scanning [65], and quantum dot tracking $[66,67]$ has enhanced our ability to investigate MSC homing as well as the behavior and organ-specific accumulation of transplanted MSCs. MRI cell tracking using SPIO is thought to be the lowest risk alternative for monitoring stem cell activity in humans due to the widely available data regarding the risk of MRI and the fact that SPIOs are Food and Drug Administration approved. Hsiao et al. [62] reported that MSCs were successfully labeled with Ferucarbotran, a clinically used ionic SPIO, without the aid of a transfection agent, and did not affect cell viability, proliferation, mitochondrial membrane potential change, reactive oxygen species production, or differentiation capacity. Approximately $45.2 \%$ of labeled MSCs can be detected at a single-level 3D gradient echo sequence and four repetitions using 1.5T MRI. Reagan and Kaplan [64] reviewed the details of MRI methods used to track cells and the potential and challenges for each technique in clinical translation. Using SPECT/CT imaging in an acute myocardial infarction model, Kraitchman et al. [65] demonstrated that the initial localization of BMMSCs was observed in the lung and the cells moved to nontarget organs such as the liver, kidney, and spleen within 24 to $48 \mathrm{~h}$ after infusion. An increase in MSCs found in the infarcted heart tissue was observed with a simultaneous decrease in the initial concentration of MSCs in the lung $24 \mathrm{~h}$ after infusion, and MSCs persisted until 7 days after injection. In addition, the labeling of BMMSCs with bioconjugated quantum dots does not alter the self-replication and differentiation potential of MSCs into chondrogenic, osteogenic, and adipogenic cells [66], and is very useful not only for tracking MSCs but also in investigating the behavioral changes of cells when MSCs are injected in combination with chemical compounds such as drugs like heparin [67]. By imaging mice with acute liver failure, Yukawa et al. [67] reported that within $10 \mathrm{~min}$ almost all transplanted AdMSCs accumulated in the lungs in the absence of heparin treatment. However, when heparin was used in combination with AdMSCs, the accumulation of the transplanted stem cells was found not only in the lungs but also in the liver, and the accumulation increased by about 30\% in the injured liver. Collectively, studies using different methods for tracking MSCs have shown an initial concentration of MSCs in the lung after transfusion $[52,65$, 67-69], after which most MSCs moved gradually to injured sites $[52,65,67,69]$ or to the liver, spleen, kidney, and bone marrow [68].

\section{Migration and Homing Potential of MSCs to Sites of Injury after Systemic Infusion}

The ability to regenerate damaged tissues is a common characteristic of multicellular organisms. A cycle of apoptosis and tissue regeneration exists in organisms, and stem cells in and around damaged tissues play among the most critical roles in wound healing and tissue regeneration [20]. It was generally assumed that factors released upon tissue damage or apoptosis mobilize and recruit stem and progenitor cells to the damaged site, where they proliferate and differentiate, eventually replacing the damaged tissues [22, 25]. However, a lack of data exists concerning the mechanisms driving MSC trafficking after intravenous, intraarterial, or local intra-tissue application compared with the relatively well-characterized leukocyte homing cascade [70]. Recently, Karp and Leng Teo [24] defined MSC homing as the "arrest of MSCs within the vasculature of the respective tissue," followed by transmigration across the endothelium. Chemokines, cytokines, and growth factors released upon injury provide migratory cues for systemically or locally administered stem cells. The cues induce upregulation of selectins and activation of integrins on the stem cell surface, enabling cells to interact with the endothelium. Stem cells subsequently adhere and transmigrate across the endothelial layer into tissues. Regarding the homing capability of MSCs, numerous studies have confirmed that systemically infused MSCs can migrate to injured, inflamed tissues and exert therapeutic effects $[21,23]$. BMMSCs, delivered intravenously to rats following myocardial infarction localize in the infarct region and improve ventricular function, while MSCs delivered intravenously to noninfarcted rats localize to the bone marrow [71]. In addition, localized abdomen irradiation has been shown to significantly enhance MSC homing specifically to radiation-injured tissues in mice [72]. Human AdMSCs infused by tail vein mobilized to celldamaged areas in an allergic rhinitis animal model [73].

Evidence confirms the involvement of chemokines or growth factors as migratory cues in MSC trafficking to the injured region [24]. The interactions of stromal cell-derived factor- $1 \alpha($ SDF- $1 \alpha)$ and C-X-C chemokine receptor type 4 (CXCR4) were found to mediate the trafficking of transplanted BMMSCs in a rat model of left hypoglossal nerve injury. Inflammatory cytokines, transforming growth factor (TGF)- $\beta 1$, interleukin (IL)- $1 \beta$, and tumor necrosis factor (TNF)- $\alpha$ upregulate the production of matrix metalloproteinases (MMPs) in MSCs, resulting in a strong stimulation of chemotactic migration through the extracellular matrix, while the chemokine SDF- $1 \alpha$ exhibited minor effects on MMP/tissue inhibitor of metalloproteinase (TIMP) expression and cell invasion [74]. BMMSCs are mobilized by chemokines that are present in the supernatants of primary cultures of human pancreatic islets culture in vitro and in vivo [75]. Human AdMSCs migrate in response to a variety of growth factors and cytokines including platelet-derived growth factor (PDGF)-AB, TGF- $\beta 1$, TNF- $\alpha$, and SDF- $1 \alpha$ [76]. Of interest, in a previous study, human AdMSCs prestimulated with TNF- $\alpha$ showed enhanced migratory activity compared to the nonpretreated control group [76]. These 
results indicate that enhancement of the homing capacity of MSCs can be achieved by modulating the response of MSCs to a variety of growth factors and cytokines, thereby improving their therapeutic potential.

\section{Homing Strategies to Enhance Efficacy and Safety of MSC Therapy}

Locally or systematically introduced MSCs have been used for cellular therapy for a variety of indications. BMMSCs have been used in a number of published interventions for a range of therapeutic applications [77, 78]. Among other applications, BMMSCs have been used to reduce clinical symptoms of osteogenesis imperfecta [79] and to treat large bone defects $[80]$, in regenerative treatments to enhance repair of pancreatic islets [81], and in infarcted myocardium [82-84]. Furthermore, BMMSCs have been applied in a variety of immunomodulatory treatments of autoimmune diseases, including Crohn's disease [85, 86], multiple sclerosis (MS) [87], and rheumatoid arthritis (RA) [88].

Like BMMSCs, AdMSCs have been demonstrated in clinical trials to be safe and suitable for introduction into the human body following culturing [89-91]. Local or systemic administration of AdMSCs was reported to have therapeutic efficacy in treating myocardial infarction [92], liver injury [93], hypoxia-ischemia-induced brain damage [94], allergic rhinitis [73], and muscular dystrophy [95]. Furthermore, the immune regulatory ability of AdMSCs has warranted their therapeutic application to treat immune-related diseases including graft versus host defense (GVHD) [96], rheumatic disease [97], and thyroiditis [98]. Systemic infusion of AdMSCs before transplantation of haploidentical hematopoietic stem cells (HSCs) controls lethal GVHD reaction of allogenic HSCs in mice [96]. Human AdMSCs reduced disease severity in experimental autoimmune thyroiditis via downregulation of Th1 cytokines and improved Th1/Th2 balance [98]. In humans, systemic administration of autologous human AdMSCs is a promising alternative to treat patients with autoimmune diseases including autoimmune ear disease, MS, polymyositis, atopic dermatitis, and RA [99]. In each of these therapeutic applications, the ability of stem cells to home to the site of injury was critical to their in vivo effects on the symptoms or underlying pathologies of these diseases.

Homing may provide an important clinical application of MSCs in the future as a cellular vehicle for anticancer therapeutics in tumors [89]. Maestroni et al. [100] reported that BMMSCs induced significant reductions in size and metastasis of lung cancer cells or melanoma cells in mice. Because tumors release a range of cytokines and preferentially recruit MSCs, stem cells may be used to deliver antitumor drugs in a preclinical setting. Studeny et al. [101, 102] demonstrated that BMMSCs transfected with IL- $1 \beta$ migrated to tumors and exerted an anticancer effect by secreting IL- $1 \beta$. Khakoo and his team [103] reported that a single injection of human BMMSCs into the tail vein of immunocompromised mice bearing Kaposi's sarcoma suppressed tumor growth by more than $50 \%$, and two injections suppressed the growth even further. Hakkarainen et al. [104] loaded MSCs derived from bone marrow and adipose tissue with oncolytic adenovirus and injected the stem cells into the tail vein of mice bearing lung and breast cancer cells. The authors found that the stem cells did not home to tumors but increased the therapeutic efficacy in lung and breast cancer cells compared to the control group injected with the virus alone. In 2007, Kucerova et al. [105] subdermally and systemically injected AdMSCs overexpressing a cancer cell cytotoxic prodrug, cytosine deaminase (CD), into mice bearing HT-29 colon cancer. Direct migration of CD-AdMSCs to the colon cancer cells was observed in vitro, and a significant inhibition of tumor growth was observed by subcutaneously or intravenously administered CD-AdMSCs in immunocompromised mice treated with 5-fluorocytosine. Qiao et al. [106] reported that human MSCs significantly inhibited the proliferation, colony-forming ability, and oncogene expression growth in malignant liver cancer cell lines, H7402 and Hep2, both in vitro and in vivo through Wnt signaling pathway. There were no cases of recurrence during the 100-day observation period that followed. In 2009, Cousin et al. [107] demonstrated that human AdMSCs strongly inhibit the proliferation of pancreatic ductal adenocarcinoma both in vitro and in vivo through altering cell cycle progression, thereby inducing tumor cell death. Canine adipose-derived stem cells loaded with interferon- $\beta$ in combination with an anticancer drug, cisplatin, was shown to inhibit the growth of melanoma cells in mice [108].

Although there may be a plateau between the number of delivered cells and improvement of clinical outcome [54], a higher number of infused MSCs are expected to give rise to a higher number of engrafted MSCs and better functional outcomes $[109,110]$. Below, several factors that affect the homing potential of MSCs will be discussed, including the quality of MSCs per se, the ability of MSCs to respond to migratory stimuli, the physiological barrier blocking MSC migration, and the inflammatory microenvironment of the body. A variety of strategies are suggested to enhance the homing of MSCs given their known homing characteristics.

5.1. Cultivating MSCs with Enhanced Migratory Ability by Optimizing Cell Culture Conditions. Highly active MSCs or progenitors are naturally attracted to signals that come from sites of injury [25]. Thus, the culture process of MSCs should maintain the characteristics of the donor/recipient's MSCs, that is, their homology. It has been demonstrated that cell culture conditions including the passage number, confluency of the passaged cells, and oxygen concentration have a significant impact on the expression of cell surface receptors of MSCs responding to migratory signals. The passage number of MSCs affects homing as MSCs have been shown to gain or lose certain surface receptors during culture. Freshly isolated MSCs display enhanced homing ability compared to their culture-expanded counterparts [111]. Homing receptors CXCR4, a chemotactic receptor for SDF- $1 \alpha$ that is upregulated in the bone marrow and in ischemic tissues, is usually absent on the surface of culture-expanded MSCs $[8,112-114]$. However, treatment of MSCs with a cocktail of cytokines in culture has been shown to induce high surface expression of CXCR4 [115]. 
The confluency of cultured MSCs prior to therapeutic infusion also affects migration potential. Lee et al. [116] investigated the differences between low-passage and lowdensity cultures versus MSCs from expanding, near-confluent cultures. Six surface markers were found preferentially expressed on early passage MSCs in low confluency cultures: podocalyxin-like protein PODXL, CD49f, CD49d, cMet, CXCR4, and CX3CR1. Sorting PODXLhi/CD49fhi cells with specific antibodies resulted in selection of early MSC progenitors that were less prone to produce lethal pulmonary emboli and increased homing to the heart in a murine myocardial infarction model. De Becker et al. [117] demonstrated that high culture confluence inhibited transendothelial migration in MSCs by increasing the production of a natural matrix MMP inhibitor, TIMP-3.

The oxygen level in cell culture conditions also influences cell homing $[118,119]$. Exposure of MSCs to hypoxic conditions increased CXCR4 and CX3 chemokine receptor 1 (CX3CR1) expression, which leads to increased migration in response to SDF-1 $\alpha$. Grafting experiments using xenotypic chick embryo showed that cultured MSCs under hypoxic conditions engrafted more efficiently compared with cells from normoxic cultures [119]. Rosová et al. [120] demonstrated that MSCs cultured in hypoxia activated the Akt signaling pathway while maintaining their viability and cell cycle rates. Hypoxic preconditioning also induced expression of cMet, the major receptor for hepatocyte growth factor, and enhanced cMet signaling. Migration rates are also increased in hypoxia, and hypoxic preconditioning increased MSC migration in Matrigel by upregulating MMPs [121].

Although a number of strategies have been discussed to improve culture conditions, the most critical aspect for clinical application of MSCs is the safety of cultured cells. Ex vivo expansion of MSCs for long-term culture alters the characteristics of MSCs, including their proliferative capacity [122], differentiation potential [123], and trophic activity [124]. We previously provided substantial guidelines for evaluating the safety of cultured MSCs by conducting in vitro and in vivo assays under good laboratory practices [91]. These assays include sterility, immunophenotyping, differentiation potential, genetic stability test, in vivo toxicology, and tumorigenicity tests in laboratory animals and in vivo safety tests in the spinal cord of patients receiving $400 \times 10^{6}$ stem cells intravenously.

5.2. Enhancing the Ability of MSCs to Respond to Migratory Stimuli. To respond to migratory signals released in sites of injury, MSCs must express surface receptors capable of sensing those signals. Various studies to modify MSCs or to enhance expression of surface markers have been explored to enhance MSC migration. A key player in MSC migration is the CXCR4-SDF- $1 \alpha$ axis [24]. Many studies have focused on ways to enhance the functional expression of CXCR4 in MSCs to migrate toward chemotactic SDF- $1 \alpha$ secreted at injury sites. Modification of CXCR4 expression with retroviral overexpression, mRNA transfection of CXCR4GFP [125], and cytokine pretreatment especially TNF- $\alpha$ resulted in increased migration toward SDF- $1 \alpha$ in vitro [76,
126]. Maijenburg et al. [127] investigated gene expression profiles involved in the process of MSC migration and found 12 differentially expressed genes in migratory MSCs compared to nonmigrating MSCs. Among them, the nuclear receptors Nur77 and Nurr1 showed the highest expression in migratory MSCs. The expression of these receptors rapidly increased under stimulation with SDF- $1 \alpha$ and PDGFBB. Genetically engineered MSCs overexpressing Nur77 or Nurr1 showed enhanced migration toward SDF-1 $\alpha$ and decreased cell proportion in S-phase cell cycle. Monocyte chemoattractant (MCP)-1 is typically expressed at sites of inflammation and can thus represent a model homing chemokine [128]. GFP-labeled MSCs expressing the MCP1 receptor, chemokine receptor (CCR) 2, on the cell surface were systemically infused into transgenic mice expressing MCP-1 specifically in the myocardium. A higher frequency of GFP-positive cells (20 cells/microscopic field) was observed in the myocardium of the transgenic mice compared to the hearts of control mice 7 and 14 days later. In another study, the upregulation of the $\alpha 4$ subunit of the VLA-4integrin on MSCs using an adenovirus vector resulted in successful dimerization with $\beta 1$-integrin and increased the homing ability of MSCs to the bone marrow by more than 10 fold as compared to nontransduced MSCs [129]. Since human MSCs do not express E-selectin ligands, Sackstein and colleagues enzymatically modified the native CD44 glycoform on MSCs into hematopoietic cell E-selectin/Lselectin ligand, resulting in increased MSC migration to the bone marrow [117].

\subsection{Modulating Physiological Barriers Blocking MSC Migra-} tion into the Site of Injury. Noninvasive administration of stem cells is more convenient and compassionate than invasive methods for cell therapy, particularly when the patient suffers from degenerative conditions or has an autoimmune indication. Blood vessels are the primary route through which MSCs circulate in the body. The vessels need to be clear of debris and broken capillaries must be fixed in order for the cells to travel to the appropriate sites in the body. Thus, the body's revascularization capacity must be adequate. If the injured area is in need of further therapy, more infused cells may be required. In these cases, the blood vessels must be clot-free, allowing cells to reach the area of injury during subsequent infusions. Furthermore, MSCs must pass through physical lung barriers and transmigrate into the tissue of injury. To solve the problems induced by microvessels and the lung, Yukawa et al. [67] proposed a combination of MSCs and heparin. When only MSCs were injected systemically in the mice, almost all transplanted MSCs were accumulated in the lungs. However, when the mice were treated with heparin, accumulations decreased in the lung and increased in the acute injured livers of these mice.

When cultured MSCs are infused into the body, what kinds of conditions can impair the ability of cells to reach their final location at the injury site? Modulating the harmful environment can improve the migration of MSCs into target tissues. Sites of tissue damage undergo chronic or acute immune responses, and MSCs migrating to these sites will 
encounter various immune cells in the local environment. Thus, MSC cellular regeneration can be influenced by immune cells in the damaged sites [130]. Liu et al. [130] presented findings that provide novel insight into how the host immune systems communicate via interferon (IFN) $-\gamma$ and TNF- $\alpha$ with transplanted MSCs during bone formation and repair. The authors demonstrated that systemic infusion of regulatory $\mathrm{T}$ cells or local administration of aspirin markedly enhanced the survival of BMMSCs and improved bone regeneration of transplanted MSCs through suppression of IFN- $\gamma$ and TNF- $\alpha$ in damaged bone sites.

\subsection{Stimulating the Target Site to Recruit MSC Mobilization.} In the acute phase of injury, factors released from damaged tissues recruit blood cells and MSCs to repair the injured site. In this regard, substantial evidence indicates that infused MSCs have higher engraftment efficiencies within sites of inflammation or injury. François et al. [58] applied total body irradiation (TBI) or TBI in combination with additional local irradiation into the abdominal area or hind leg of mice. The authors found that the engraftment level of systemically infused MSCs was higher in mice subjected to TBI compared to nonirradiated mice. Cho et al. [73] also demonstrated that inflammatory stimuli of allergic rhinitis induced the homing of intravenously administered hAdMSCs to cell-damaged areas. Taken together, the evidences indicate that signals are required to recruit MSCs with high efficiency, which is critical for improving the clinical benefits of MSCs. However, in a variety of clinical indications, MSCs are administered to damaged tissues at the subchronic or chronic phases of injury, in which the migratory signals for MSCs may be minimal or absent. Thus, exogenous stimuli are necessary to recruit infused MSCs into subchronic or chronic phases of injury sites for high efficacy of MSC therapy.

In this regard, electric stimuli can be a good candidate directing MSCs migration to injured sites. Evidence demonstrates that electrical stimulation (ES) induces the migration and stimulation of adult cells, including stem cells, and improves the clinical benefit. Electrical current applied to wounded tissue activates and migrates fibroblasts, which play a critical role in wound healing [131, 132]. Gardner et al. [133] performed a meta-analysis on the effect of ES on chronic wound healing in human patients and reported that ES increased the rate of chronic wound healing to $144 \%$ that of the control in 24 studies. In an animal model of spinal cord injury, application of an electrical field (EF) resulted in functional improvement [134]. On the basis of the effects of EFs on functional improvement in animal models of spinal cord injury (SCI), Shapiro et al. [135] applied weak EF stimulation in human SCI in a phase I trial and reported considerable clinical benefit. Perry et al. [136] applied degenerate electrical waveforms in the treatment of skin scarring in 30 patients with over 140 scars with longterm pain and itching. After monitoring for 6 months, the authors reported that ES treatment resulted in a clinically and statistically significant reduction of symptoms and scar scores. Zhao et al. [137] demonstrated that physiological EF of $\sim 25 \mathrm{mV} / \mathrm{mm}$ in vitro directed the migration of cultured
BMMSCs mainly to the anode. Increasing the EFs enhanced the migration of the MSC and peaked the response at $300 \mathrm{mV} / \mathrm{mL}$ at a rate of $42 \pm 1 \mu \mathrm{m} / \mathrm{h}$, around double the migration rate of the control (no EF). Of importance, EF did not influence cell senescence, phenotype, or the osteogenic potential of MSCs, regardless of passage number within the range tested (P3-P10). Recently, it has been demonstrated the combination of MSC transplantation with ES can be a therapeutic tool to improve the efficacy of transplantation. $\mathrm{Wu}$ et al. [138] demonstrated that implanted spike wave ES improved the survival of BMMSCs after transplantation compared to BMMSCs transplantation or ES treatment alone using an in vivo rat model of spinal cord injury. Furthermore, analysis of functional parameters demonstrated improved functional recovery in the BMMSCs + ES groups. Taken together, it can be hypothesized that applying ES around injured sites can direct migration of exogenously infused MSCs and enhance the migration of MSCs during the healing process. This hypothesis requires further verification.

\section{Conclusions}

The efforts of researchers to establish the safety of MSC infusion and their effects in vivo have led to the application of MSCs for the treatment of various tissue degenerative indications in humans [99]. Thus far, most of the procedures involve local administration or direct injection [http://www.clinicaltrials.gov/]. However, for conditions such as Alzheimer's, Parkinson's, liver disease, renal failure, and autoimmune diseases, the delivery of MSCs by systemic infusion can be minimally invasive and convenient. To make a systemic infusion efficacious, more MSCs are needed by comparison to local delivery. MSCs can be expanded via in vitro culture, which unfortunately presents high costs. Thus, further research is required to understand the factors affecting the efficiency of MSC migration and to determine strategies to remove harmful factors and improve homing of MSCs to the area of injury. New strategies could mean smaller quantities of MSCs necessary for infusion, thereby attaining the intended therapeutic goal with greatest efficiency and efficacy. To achieve this goal, cell migration and tracking studies must be conducted in various in vivo environments along with in vitro laboratory studies. Through these studies, optimized culture conditions can be established to cultivate MSCs with enhanced homing ability and expressing the appropriate homing receptor. This is also essential to improve vascular conditions, so that introduced cells can easily migrate to damaged sites. In addition, it is critical to determine exogenous stimuli such as ES to recruit infused MSCs into the subchronic or chronic injury sites. Ultimately, the future of stem cell therapy depends, as does so much of science in general, on understanding the nature of responses to illness. Just as bees are naturally attracted to flowers and men are attracted to women, the philosophy of research of MSC migration and homing should focus on the nature of life. 


\section{References}

[1] A. J. Nauta and W. E. Fibbe, "Immunomodulatory properties of mesenchymal stromal cells," Blood, vol. 110, no. 10, pp. 3499-3506, 2007.

[2] J. Ankrum and J. M. Karp, "Mesenchymal stem cell therapy: two steps forward, one step back," Trends in Molecular Medicine, vol. 16, no. 5, pp. 203-209, 2010.

[3] B. Parekkadan and J. M. Milwid, "Mesenchymal stem cells as therapeutics," Annual Review of Biomedical Engineering, vol. 12, pp. 87-117, 2010.

[4] Y. L. Si, Y. L. Zhao, H. J. Hao, X. B. Fu, and W. D. Han, "MSCs: biological characteristics, clinical applications and their outstanding concerns," Ageing Research Reviews, vol. 10, no. 1, pp. 93-103, 2011.

[5] E. Ben-Ami, S. Berrih-Aknin, and A. Miller, "Mesenchymal stem cells as an immunomodulatory therapeutic strategy for autoimmune diseases," Autoimmunity Reviews, vol. 10, no. 7, pp. 410-415, 2011.

[6] M. F. Pittenger, A. M. Mackay, S. C. Beck et al., "Multilineage potential of adult human mesenchymal stem cells," Science, vol. 284, no. 5411, pp. 143-147, 1999.

[7] B. S. Dhinsa and A. B. Adesida, "Current clinical therapies for cartilage repair, their limitation and the role of stem cells," Current Stem Cell Research and Therapy, vol. 7, no. 2, pp. 143148, 2012.

[8] D. G. Phinney and D. J. Prockop, "Concise review: mesenchymal stem/multipotent stromal cells: the state of transdifferentiation and modes of tissue repair-current views," Stem Cells, vol. 25, no. 11, pp. 2896-2902, 2007.

[9] R. J. Bergman, D. Gazit, A. J. Kahn, H. Gruber, S. Mcdougall, and T. J. Hahn, "Age-related changes in osteogenic stem cells in mice," Journal of Bone and Mineral Research, vol. 11, no. 5, pp. 568-577, 1996.

[10] H. T. Chen, M. J. Lee, C. H. Chen et al., "Proliferation and differentiation potential of human adipose-derived mesenchymal stem cells isolated from elderly patients with osteoporotic fractures," Journal of Cellular and Molecular Medicine, vol. 16, no. 3, pp. 582-593, 2012.

[11] A. Stolzing, H. Colley, and A. Scutt, "Effect of age and diabetes on the response of mesenchymal progenitor cells to fibrin matrices," International Journal of Biomaterials, vol. 2011, Article ID 378034, 9 pages, 2011.

[12] B. A. Huibregtse, B. Johnstone, V. M. Goldberg, and A. I. Caplan, "Effect of age and sampling site on the chondroosteogenic potential of rabbit marrow-derived mesenchymal progenitor cells," Journal of Orthopaedic Research, vol. 18, no. 1, pp. 18-24, 2000.

[13] M. Lavasani, A. R. Robinson, A. Lu et al., "Muscle-derived stem/progenitor cell dysfunction limits healthspan and lifespan in a murine progeria model," Nature Communications, vol. 3, article 608, 2012.

[14] S. C. Mendes, J. M. Tibbe, M. Veenhof et al., "Bone tissueengineered implants using human bone marrow stromal cells: effect of culture conditions and donor age," Tissue Engineering, vol. 8, no. 6, pp. 911-920, 2002.

[15] Y. Jing and Y. Jian-xiong, "3-D spheroid culture of bone marrow mesenchymal stem cell of rhesus monkey with improved multi-differentiation potential to epithelial progenitors and neuron in vitro," Clinical and Experimental Ophthalmology, vol. 39, pp. 808-819, 2011.

[16] E. Birmingham, G. L. Niebur, P. E. Mchugh, G. Shaw, F. P. Barry, and L. M. McNamara, "Osteogenic differentiation of mesenchymal stem cells is regulated by osteocyte and osteoblast cells in a simplified bone niche," European Cells and Materials, vol. 23, pp. 13-27, 2012.

[17] E. J. Sheehy, C. T. Buckley, and D. J. Kelly, "Oxygen tension regulates the osteogenic, chondrogenic and endochondral phenotype of bone marrow derived mesenchymal stem cells," Biochemical and Biophysical Research Communications, vol. 417, no. 1, pp. 305-310, 2012.

[18] A. Mirsaidi, K. N. Kleinhans, M. Rimann et al., "Telomere length, telomerase activity and osteogenic differentiation are maintained in adipose-derived stromal cells from senile osteoporotic SAMP6 mice," Journal of Tissue Engineering and Regenerative Medicine, vol. 6, no. 5, pp. 378-390, 2012.

[19] W. Wagner, P. Horn, M. Castoldi et al., "Replicative senescence of mesenchymal stem cells: a continuous and organized process," PLoS ONE, vol. 3, no. 5, Article ID e2213, 2008.

[20] T. A. Rando, "Stem cells, ageing and the quest for immortality," Nature, vol. 441, no. 7097, pp. 1080-1086, 2006.

[21] A. Chapel, J. M. Bertho, M. Bensidhoum et al., "Mesenchymal stem cells home to injured tissues when co-infused with hematopoietic cells to treat a radiation-induced multi-organ failure syndrome," Journal of Gene Medicine, vol. 5, no. 12, pp. 1028-1038, 2003.

[22] G. C. Gurtner, S. Werner, Y. Barrandon, and M. T. Longaker, "Wound repair and regeneration," Nature, vol. 453, no. 7193, pp. 314-321, 2008.

[23] E. Chavakis, C. Urbich, and S. Dimmeler, "Homing and engraftment of progenitor cells: a prerequisite for cell therapy," Journal of Molecular and Cellular Cardiology, vol. 45, no. 4, pp. 514-522, 2008.

[24] J. M. Karp and G. S. Leng Teo, "Mesenchymal stem cell homing: the devil is in the details," Cell Stem Cell, vol. 4, no. 3, pp. 206-216, 2009.

[25] F. Li, Q. Huang, J. Chen et al., "Apoptotic cells activate the "phoenix rising" pathway to promote wound healing and tissue regeneration," Science Signaling, vol. 3, no. 110, p. ra13, 2010.

[26] L. da Silva Meirelles, A. I. Caplan, and N. B. Nardi, "In search of the in vivo identity of mesenchymal stem cells," Stem Cells, vol. 26, no. 9, pp. 2287-2299, 2008.

[27] A. J. Friedenstein, K. V. Petrakova, A. I. Kurolesova, and G. P. Frolova, "Heterotopic of bone marrow. Analysis of precursor cells for osteogenic and hematopoietic tissues," Transplantation, vol. 6, no. 2, pp. 230-247, 1968.

[28] M. Dominici, K. Le Blanc, I. Mueller et al., "Minimal criteria for defining multipotent mesenchymal stromal cells. The International Society for Cellular Therapy position statement," Cytotherapy, vol. 8, no. 4, pp. 315-317, 2006.

[29] J. Chen, R. Liu, Y. Yang et al., "The simulated microgravity enhances the differentiation of mesenchymal stem cells into neurons," Neuroscience Letters, vol. 505, no. 2, pp. 171-175, 2011.

[30] N. Ahmadi, S. Razavi, M. Kazemi, and S. Oryan, "Stability of neural differentiation in human adipose derived stem cells by two induction protocols," Tissue and Cell, vol. 44, no. 2, pp. 87-94, 2012.

[31] S. Jang, H. H. Cho, Y. B. Cho, J. S. Park, and H. S. Jeong, "Functional neural differentiation of human adipose tissuederived stem cells using bFGF and forskolin," BMC Cell Biology, vol. 11, article 25, 2010.

[32] Y. Du, D. S. Roh, M. L. Funderburgh et al., "Adipose-derived stem cells differentiate to keratocytes in vitro," Molecular Vision, vol. 16, pp. 2680-2689, 2010.

[33] G. Jin, M. P. Prabhakaran, and S. Ramakrishna, "Stem cell differentiation to epidermal lineages on electrospun 
nanofibrous substrates for skin tissue engineering," Acta Biomaterialia, vol. 7, no. 8, pp. 3113-3122, 2011.

[34] M. Ayatollahi, M. Soleimani, S. Z. Tabei, and M. K. Salmani, "Hepatogenic differentiation of mesenchymal stem cells induced by insulin like growth factor-I," World Journal of Stem Cells, vol. 3, pp. 113-121, 2011.

[35] F. Al Battah, J. De Kock, T. Vanhaecke, and V. Rogiers, "Current status of human adipose-derived stem cells: differentiation into hepatocyte-like cells," The Scientific World Journal, vol. 11, pp. 1568-1581, 2011.

[36] D. R. Bhandari, K. W. Seo, B. Sun et al., "The simplest method for in vitro $\beta$-cell production from human adult stem cells," Differentiation, vol. 82, pp. 144-152, 2011.

[37] P. Bianco, P. G. Robey, and P. J. Simmons, "Mesenchymal stem cells: revisiting history, concepts, and assays," Cell Stem Cell, vol. 2, no. 4, pp. 313-319, 2008.

[38] C. K. Rebelatto, A. M. Aguiar, M. P. Moretao et al., "Dissimilar differentiation of mesenchymal stem cells from bone marrow, umbilical cord blood, and adipose tissue," Experimental Biology and Medicine, vol. 233, no. 7, pp. 901913, 2008.

[39] F. Alviano, V. Fossati, C. Marchionni et al., "Term amniotic membrane is a high throughput source for multipotent mesenchymal stem cells with the ability to differentiate into endothelial cells in vitro," BMC Developmental Biology, vol. 7, article 11, 2007.

[40] M. Kassem, M. Kristiansen, and B. M. Abdallah, "Mesenchymal stem cells: cell biology and potential use in therapy," Basic and Clinical Pharmacology and Toxicology, vol. 95, no. 5, pp. 209-214, 2004.

[41] O. Abla, J. Friedman, and J. Doyle, "Performing bone marrow aspiration and biopsy in children: recommended guidelines," Paediatrics and Child Health, vol. 13, no. 6, pp. 499-501, 2008.

[42] S. Gronthos, A. C. Zannettino, S. J. Hay et al., "Molecular and cellular characterisation of highly purified stromal stem cells derived from human bone marrow," Journal of Cell Science, vol. 116, no. 9, pp. 1827-1835, 2003.

[43] H. Ohgushi, N. Kotobuki, H. Funaoka et al., "Tissue engineered ceramic artificial joint-ex vivo osteogenic differentiation of patient mesenchymal cells on total ankle joints for treatment of osteoarthritis," Biomaterials, vol. 26, no. 22, pp. 4654-4661, 2005.

[44] K. Stenderup, J. Justesen, C. Clausen, and M. Kassem, "Aging is associated with decreased maximal life span and accelerated senescence of bone marrow stromal cells," Bone, vol. 33, no. 6, pp. 919-926, 2003.

[45] P. A. Zuk, M. Zhu, P. Ashjian et al., "Human adipose tissue is a source of multipotent stem cells," Molecular Biology of the Cell, vol. 13, no. 12, pp. 4279-4295, 2002.

[46] H. Mizuno, "Adipose-derived stem cells for tissue repair and regeneration: ten years of research and a literature review," Journal of Nippon Medical School, vol. 76, no. 2, pp. 56-66, 2009.

[47] A. Sen, Y. R. Lea-Currie, D. Sujkowska et al., "Adipogenic potential of human adipose derived stromal cells from multiple donors is heterogeneous," Journal of Cellular Biochemistry, vol. 81, no. 2, pp. 312-319, 2001.

[48] O. Hayashi, Y. Katsube, M. Hirose, H. Ohgushi, and H. Ito, "Comparison of osteogenic ability of rat mesenchymal stem cells from bone marrow, periosteum, and adipose tissue," Calcified Tissue International, vol. 82, no. 3, pp. 238-247, 2008.

[49] S. M. Devine, C. Cobbs, M. Jennings, A. Bartholomew, and R. Hoffman, "Mesenchymal stem cells distribute to a wide range of tissues following systemic infusion into nonhuman primates," Blood, vol. 101, no. 8, pp. 2999-3001, 2003.

[50] H. Kawada, J. Fujita, K. Kinjo et al., "Nonhematopoietic mesenchymal stem cells can be mobilized and differentiate into cardiomyocytes after myocardial infarction," Blood, vol. 104, no. 12, pp. 3581-3587, 2004.

[51] N. Nagaya, T. Fujii, T. Iwase et al., "Intravenous administration of mesenchymal stem cells improves cardiac function in rats with acute myocardial infarction through angiogenesis and myogenesis," American Journal of Physiology, vol. 287, no. 6, pp. H2670-H2676, 2004.

[52] E. Deak, E. Seifried, and R. Henschler, "Homing pathways of mesenchymal stromal cells (MSCs) and their role in clinical applications," International Reviews of Immunology, vol. 29, no. 5, pp. 514-529, 2010.

[53] Y. Horita, O. Honmou, K. Harada, K. Houkin, H. Hamada, and J. D. Kocsis, "Intravenous administration of glial cell line-derived neurotrophic factor gene-modified human mesenchymal stem cells protects against injury in a cerebral ischemia model in the adult rat," Journal of Neuroscience Research, vol. 84, no. 7, pp. 1495-1504, 2006.

[54] Y. Omori, O. Honmou, K. Harada, J. Suzuki, K. Houkin, and J. D. Kocsis, "Optimization of a therapeutic protocol for intravenous injection of human mesenchymal stem cells after cerebral ischemia in adult rats," Brain Research, vol. 1236, pp. 30-38, 2008.

[55] I. M. Barbash, P. Chouraqui, J. Baron et al., "Systemic delivery of bone marrow-derived mesenchymal stem cells to the infarcted myocardium: feasibility, cell migration, and body distribution," Circulation, vol. 108, no. 7, pp. 863-868, 2003.

[56] A. Mahmood, D. Lu, C. Qu, A. Coussev, and M. Chopp, "Human marrow stromal cell treatment provides longlasting benefit after traumatic brain injury in rats," Neurosurgery, vol. 57, no. 5, pp. 1026-1031, 2005.

[57] M. Fatar, M. Stroick, M. Griebe et al., "Lipoaspirate-derived adult mesenchymal stem cells improve functional outcome during intracerebral hemorrhage by proliferation of endogenous progenitor cells: stem cells in intracerebral hemorrhages," Neuroscience Letters, vol. 443, no. 3, pp. 174178, 2008.

[58] S. François, M. Bensidhoum, M. Mouiseddine et al., "Local irradiation not only induces homing of human mesenchymal stem cells at exposed sites but promotes their widespread engraftment to multiple organs: a study of their quantitative distribution after irradiation damage," Stem Cells, vol. 24, no. 4, pp. 1020-1029, 2006.

[59] L. A. Ortiz, F. Gambelli, C. McBride et al., "Mesenchymal stem cell engraftment in lung is enhanced in response to bleomycin exposure and ameliorates its fibrotic effects," Proceedings of the National Academy of Sciences of the United States of America, vol. 100, no. 14, pp. 8407-8411, 2003.

[60] W. Jiang, A. Ma, T. Wang et al., "Homing and differentiation of mesenchymal stem cells delivered intravenously to ischemic myocardium in vivo: a time-series study," Pflugers Archiv European Journal of Physiology, vol. 453, no. 1, pp. 4352, 2006.

[61] M. Morigi, M. Introna, B. Imberti et al., "Human bone marrow mesenchymal stem cells accelerate recovery of acute renal injury and prolong survival in mice," Stem Cells, vol. 26, no. 8, pp. 2075-2082, 2008.

[62] J. K. Hsiao, M. F. Tai, H. H. Chu et al., "Magnetic nanoparticle labeling of mesenchymal stem cells without transfection agent: cellular behavior and capability of detection with 
clinical 1.5 T magnetic resonance at the single cell level," Magnetic Resonance in Medicine, vol. 58, no. 4, pp. 717-724, 2007.

[63] Y. S. Song and J. H. Ku, "Monitoring transplanted human mesenchymal stem cells in rat and rabbit bladders using molecular magnetic resonance imaging," Neurourology and Urodynamics, vol. 26, no. 4, pp. 584-593, 2007.

[64] M. R. Reagan and D. L. Kaplan, "Concise review: mesenchymal stem cell tumor-homing: detection methods in disease model systems," Stem Cells, vol. 29, no. 6, pp. 920-927, 2011.

[65] D. L. Kraitchman, M. Tatsumi, W. D. Gilson et al., "Dynamic imaging of allogeneic mesenchymal stem cells trafficking to myocardial infarction," Circulation, vol. 112, no. 10, pp. 1451-1461, 2005.

[66] B. S. Shah, P. A. Clark, E. K. Moioli, M. A. Stroscio, and J. J. Mao, "Labeling of mesenchymal stem cells by bioconjugated quantum dots," Nano Letters, vol. 7, no. 10, pp. 3071-3079, 2007.

[67] H. Yukawa, M. Watanabe, N. Kaji et al., "Monitoring transplanted adipose tissue-derived stem cells combined with heparin in the liver by fluorescence imaging using quantum dots," Biomaterials, vol. 33, no. 7, pp. 2177-2186, 2012.

[68] J. Gao, J. E. Dennis, R. F. Muzic, M. Lundberg, and A. I. Caplan, "The dynamic in vivo distribution of bone marrowderived mesenchymal stem cells after infusion," Cells Tissues Organs, vol. 169, no. 1, pp. 12-20, 2001.

[69] R. H. Lee, A. A. Pulin, M. J. Seo et al., "Intravenous hMSCs improve myocardial infarction in mice because cells embolized in lung are activated to secrete the anti-inflammatory protein TSG-6," Cell Stem Cell, vol. 5, no. 1, pp. 54-63, 2009.

[70] T. A. Springer, "Traffic signals for lymphocyte recirculation and leukocyte emigration: the multistep paradigm," Cell, vol. 76, no. 2, pp. 301-314, 1994.

[71] T. Saito, J. Kuang, B. Bittira, A. Al-Khaldi, and R. C. J. Chiu, "Xenotransplant cardiac chimera: immune tolerance of adult stem cells," Annals of Thoracic Surgery, vol. 74, no. 1, pp. 19$24,2002$.

[72] M. Mouiseddine, S. François, A. Semont et al., "Human mesenchymal stem cells home specifically to radiation-injured tissues in a non-obese diabetes/severe combined immunodeficiency mouse model," British Journal of Radiology, vol. 80, no. 1, pp. S49-S55, 2007.

[73] K. S. Cho, H. K. Park, H. Y. Park et al., "IFATS collection: immunomodulatory effects of adipose tissue-derived stem cells in an allergic rhinitis mouse model," Stem Cells, vol. 27, no. 1, pp. 259-265, 2009.

[74] C. Ries, V. Egea, M. Karow, H. Kolb, M. Jochum, and P. Neth, "MMP-2, MT1-MMP, and TIMP-2 are essential for the invasive capacity of human mesenchymal stem cells: differential regulation by inflammatory cytokines," Blood, vol. 109, no. 9, pp. 4055-4063, 2007.

[75] V. Sordi, M. L. Malosio, F. Marchesi et al., "Bone marrow mesenchymal stem cells express a restricted set of functionally active chemokine receptors capable of promoting migration to pancreatic islets," Blood, vol. 106, no. 2, pp. 419427, 2005.

[76] S. J. Baek, S. K. Kang, and J. C. Ra, "In vitro migration capacity of human adipose-derived mesenchymal stem cells and their expression of a distinct set of chemokine and growth factor receptors," Experimental and Molecular Medicine, vol. 43, no. 10, pp. 596-603, 2011.

[77] H. K. Salem and C. Thiemermann, "Mesenchymal stromal cells: current understanding and clinical status," Stem Cells, vol. 28, no. 3, pp. 585-596, 2010.
[78] J. Tolar, K. Le Blanc, A. Keating, and B. R. Blazar, "Concise review: hitting the right spot with mesenchymal stromal cells," Stem Cells, vol. 28, no. 8, pp. 1446-1455, 2010.

[79] E. M. Horwitz, D. J. Prockop, L. A. Fitzpatrick et al., "Transplantability and therapeutic effects of bone marrow-derived mesenchymal cells in children with osteogenesis imperfecta," Nature Medicine, vol. 5, no. 3, pp. 309-313, 1999.

[80] R. Quarto, M. Mastrogiacomo, R. Cancedda et al., "Repair of large bone defects with the use of autologous bone marrow stromal cells," The New England Journal of Medicine, vol. 344, no. 5, pp. 385-386, 2001.

[81] R. H. Lee, M. J. Seo, R. L. Reger et al., "Multipotent stromal cells from human marrow home to and promote repair of pancreatic islets and renal glomeruli in diabetic NOD/scid mice," Proceedings of the National Academy of Sciences of the United States of America, vol. 103, no. 46, pp. 17438-17443, 2006.

[82] H. Kawada, J. Fujita, K. Kinjo et al., "Nonhematopoietic mesenchymal stem cells can be mobilized and differentiate into cardiomyocytes after myocardial infarction," Blood, vol. 104, no. 12, pp. 3581-3587, 2004.

[83] S. L. Chen, W. W. Fang, F. Ye et al., "Effect on left ventricular function of intracoronary transplantation of autologous bone marrow mesenchymal stem cell in patients with acute myocardial infarction," American Journal of Cardiology, vol. 94, no. 1, pp. 92-95, 2004.

[84] R. S. Ripa, M. Haack-Sorensen, Y. Wang et al., "Bone marrow-derived mesenchymal cell mobilization by granulocytecolony stimulating factor after acute myocardial infarction: results from the Stem Cells in Myocardial Infarction (STEMMI) trial," Circulation, vol. 116, no. 11, pp. I24-I30, 2007.

[85] M. Duijvestein, A. C. Vos, H. Roelofs et al., "Autologous bone marrow-derived mesenchymal stromal cell treatment for refractory luminal Crohn's disease: results of a phase I study," Gut, vol. 59, no. 12, pp. 1662-1669, 2010.

[86] P. Taupin, "OTI-010 Osiris therapeutics/JCR pharmaceuticals," Current Opinion in Investigational Drugs, vol. 7, no. 5, pp. 473-481, 2006.

[87] E. Zappia, S. Casazza, E. Pedemonte et al., "Mesenchymal stem cells ameliorate experimental autoimmune encephalomyelitis inducing T-cell anergy," Blood, vol. 106, no. 5, pp. 1755-1761, 2005.

[88] A. Augello, R. Tasso, S. M. Negrini, R. Cancedda, and G. Pennesi, "Cell therapy using allogeneic bone marrow mesenchymal stem cells prevents tissue damage in collageninduced arthritis," Arthritis and Rheumatism, vol. 56, no. 4, pp. 1175-1186, 2007.

[89] S. Ciavarella, M. Dominici, F. Dammacco, and F. Silvestris, "Mesenchymal stem cells: a new promise in anticancer therapy," Stem Cells and Development, vol. 20, no. 1, pp. 110, 2011.

[90] B. Fang, Y. Song, L. Liao, Y. Zhang, and R. C. Zhao, "Favorable response to human adipose tissue-derived mesenchymal stem cells in steroid-refractory acute graft-versus-host disease," Transplantation Proceedings, vol. 39, no. 10, pp. 33583362, 2007.

[91] J. C. Ra, I. S. Shin, S. H. Kim et al., "Safety of intravenous infusion of human adipose tissue-derived mesenchymal stem cells in animals and humans," Stem Cells and Development, vol. 20, no. 8, pp. 1297-1308, 2011.

[92] L. Cai, B. H. Johnstone, T. G. Cook et al., "IFATS collection: human adipose tissue-derived stem cells induce angiogenesis and nerve sprouting following myocardial infarction, in 
conjunction with potent preservation of cardiac function," Stem Cells, vol. 27, no. 1, pp. 230-237, 2009.

[93] A. Banas, T. Teratani, Y. Yamamoto et al., "IFATS collection: in vivo therapeutic potential of human adipose tissue mesenchymal stem cells after transplantation into mice with liver injury," Stem Cells, vol. 26, no. 10, pp. 2705-2712, 2008.

[94] X. Wei, Z. Du, L. Zhao et al., "IFATS collection: the conditioned media of adipose stromal cells protect against hypoxia-ischemia-induced brain damage in neonatal rats," Stem Cells, vol. 27, no. 2, pp. 478-488, 2009.

[95] F. Bacou, R. B. el Andalousi, P. A. Daussin et al., "Transplantation of adipose tissue-derived stromal cells increases mass and functional capacity of damaged skeletal muscle," Cell Transplantation, vol. 13, no. 2, pp. 103-111, 2004.

[96] R. Yañez, M. L. Lamana, J. García-Castro, I. Colmenero, M. Ramírez, and J. A. Bueren, "Adipose tissue-derived mesenchymal stem cells have in vivo immunosuppressive properties applicable for the control of the graft-versus-host disease," Stem Cells, vol. 24, no. 11, pp. 2582-2591, 2006.

[97] B. Zhou, J. Yuan, Y. Zhou et al., "Administering human adipose-derived mesenchymal stem cells to prevent and treat experimental arthritis," Clinical Immunology, vol. 141, no. 3, pp. 328-337, 2011.

[98] E. W. Choi, I. S. Shin, H. W. Lee et al., "Transplantation of CTLA4Ig gene-transduced adipose tissue-derived mesenchymal stem cells reduces inflammatory immune response and improves Th1/Th2 balance in experimental autoimmune thyroiditis," Journal of Gene Medicine, vol. 13, no. 1, pp. 316, 2011.

[99] J. C. Ra, S. K. Kang, I. S. Shin et al., "Stem cell treatment for patients with autoimmune disease by systemic infusion of culture-expanded autologous adipose tissue derived mesenchymal stem cells," Journal of Translational Medicine, vol. 9, no. 1, article 181, 2011.

[100] G. J. Maestroni, E. Hertens, and P. Galli, "Factor(s) from nonmacrophage bone marrow stromal cells inhibit Lewis lung carcinoma and B16 melanoma growth in mice," Cellular and Molecular Life Sciences, vol. 55, no. 4, pp. 663-667, 1999.

[101] M. Studeny, F. C. Marini, R. E. Champlin, C. Zompetta, I. J. Fidler, and M. Andreeff, "Bone marrow-derived mesenchymal stem cells as vehicles for interferon- $\beta$ delivery into tumors," Cancer Research, vol. 62, no. 13, pp. 3603-3608, 2002.

[102] M. Studeny, F. C. Marini, J. L. Dembinski et al., "Mesenchymal stem cells: potential precursors for tumor stroma and targeted-delivery vehicles for anticancer agents," Journal of the National Cancer Institute, vol. 96, no. 21, pp. 1593-1603, 2004.

[103] A. Y. Khakoo, S. Pati, S. A. Anderson et al., "Human mesenchymal stem cells exert potent antitumorigenic effects in a model of Kaposi's sarcoma," Journal of Experimental Medicine, vol. 203, no. 5, pp. 1235-1247, 2006.

[104] T. Hakkarainen, M. Särkioja, P. Lehenkari et al., "Human mesenchymal stem cells lack tumor tropism but enhance the antitumor activity of oncolytic adenoviruses in orthotopic lung and breast tumors," Human Gene Therapy, vol. 18, no. 7, pp. 627-641, 2007.

[105] L. Kucerova, V. Altanerova, M. Matuskova, S. Tyciakova, and C. Altaner, "Adipose tissue-derived human mesenchymal stem cells mediated prodrug cancer gene therapy," Cancer Research, vol. 67, no. 13, pp. 6304-6313, 2007.

[106] L. Qiao, Z. Xu, T. Zhao et al., "Suppression of tumorigenesis by human mesenchymal stem cells in a hepatoma model," Cell Research, vol. 18, no. 4, pp. 500-507, 2008.
[107] B. Cousin, E. Ravet, S. Poglio et al., "Adult stromal cells derived from human adipose tissue provoke pancreatic cancer cell death both in vitro and in vivo," PLoS ONE, vol. 4, no. 7, article e6278, 2009.

[108] K. W. Seo, H. W. Lee, Y. I. Oh et al., "Anti-tumor effects of canine adipose tissue-derived mesenchymal stromal cellbased interferon- $\beta$ gene therapy and cisplatin in a mouse melanoma model," Cytotherapy, vol. 13, no. 8, pp. 944-955, 2011.

[109] J. Chen, Y. Li, L. Wang et al., "Therapeutic benefit of intravenous administration of bone marrow stromal cells after cerebral ischemia in rats," Stroke, vol. 32, no. 4, pp. 10051011, 2001.

[110] J. Wu, Z. Sun, H. S. Sun et al., "Intravenously administered bone marrow cells migrate to damaged brain tissue and improve neural function in ischemic rats," Cell Transplantation, vol. 16, no. 10, pp. 993-1005, 2008.

[111] W. J. C. Rombouts and R. E. Ploemacher, "Primary murine MSC show highly efficient homing to the bone marrow but lose homing ability following culture," Leukemia, vol. 17, no. 1, pp. 160-170, 2003.

[112] R. F. Wynn, C. A. Hart, C. Corradi-Perini et al., "A small proportion of mesenchymal stem cells strongly expresses functionally active CXCR4 receptor capable of promoting migration to bone marrow," Blood, vol. 104, no. 9, pp. 26432645,2004

[113] B. Ruster, S. Gottig, R. J. Ludwig et al., "Mesenchymal stem cells display coordinated rolling and adhesion behavior on endothelial cells," Blood, vol. 108, no. 12, pp. 3938-3944, 2006.

[114] R. Sackstein, J. S. Merzaban, D. W. Cain et al., "Ex vivo glycan engineering of CD44 programs human multipotent mesenchymal stromal cell trafficking to bone," Nature Medicine, vol. 14, no. 2, pp. 181-187, 2008.

[115] M. Shi, J. Li, L. Liao et al., "Regulation of CXCR4 expression in human mesenchymal stem cells by cytokine treatment: role in homing efficiency in NOD/SCID mice," Haematologica, vol. 92, no. 7, pp. 897-904, 2007.

[116] R. H. Lee, M. J. Seo, A. A. Pulin, C. A. Gregory, J. Ylostalo, and D. J. Prockop, "The CD34-like protein PODXL and alpha6-integrin (CD49f) identify early progenitor MSCs with increased clonogenicity and migration to infarcted heart in mice," Blood, vol. 113, no. 4, pp. 816-826, 2009.

[117] A. De Becker, P. Van Hummelen, M. Bakkus et al., "Migration of culture-expanded human mesenchymal stem cells through bone marrow endothelium is regulated by matrix metalloproteinase- 2 and tissue inhibitor of metalloproteinase-3," Haematologica, vol. 92, no. 4, pp. 440-449, 2007.

[118] H. Liu, W. Xue, G. Ge et al., "Hypoxic preconditioning advances CXCR4 and CXCR7 expression by activating HIF$1 \alpha$ in MSCs," Biochemical and Biophysical Research Communications, vol. 401, no. 4, pp. 509-515, 2010.

[119] S. C. Hung, R. R. Pochampally, S. C. Hsu et al., "Shortterm exposure of multipotent stromal cells to low oxygen increases their expression of CX3CR1 and CXCR4 and their engraftment in vivo," PLoS One, vol. 2, no. 5, article e416, 2007.

[120] I. Rosová, M. Dao, B. Capoccia, D. Link, and J. A. Nolta, "Hypoxic preconditioning results in increased motility and improved therapeutic potential of human mesenchymal stem cells," Stem Cells, vol. 26, no. 8, pp. 2173-2182, 2008.

[121] B. Annabi, Y. T. Lee, S. Turcotte et al., "Hypoxia promotes murine bone-marrow-derived stromal cell migration and tube formation," Stem Cells, vol. 21, no. 3, pp. 337-347, 2003. 
[122] S. Wislet-Gendebien, P. Leprince, G. Moonen, and B. Rogister, "Regulation of neural markers nestin and GFAP expression by cultivated bone marrow stromal cells," Journal of Cell Science, vol. 116, no. 16, pp. 3295-3302, 2003.

[123] M. M. Bonab, K. Alimoghaddam, F. Talebian, S. H. Ghaffari, A. Ghavamzadeh, and B. Nikbin, "Aging of mesenchymal stem cell in vitro," BMC Cell Biology, vol. 7, article 14, 2006.

[124] A. Briquet, S. Dubois, S. Bekaert, M. Dolhet, Y. Beguin, and A. Gothot, "Prolonged ex vivo culture of human bone marrow mesenchymal stem cells influences their supportive activity toward NOD/SCID-repopulating cells and committed progenitor cells of B lymphoid and myeloid lineages," Haematologica, vol. 95, no. 1, pp. 47-56, 2010.

[125] M. F. Ryser, F. Ugarte, S. Thieme, M. Bornhäuser, A. RoesenWolff, and S. Brenner, "mRNA transfection of CXCR4GFP fusion-simply generated by PCR - results in efficient migration of primary human mesenchymal stem cells," Tissue Engineering C, vol. 14, no. 3, pp. 179-184, 2008.

[126] Q. Xiao, S. K. Wang, H. Tian et al., "TNF- $\alpha$ increases bone marrow mesenchymal stem cell migration to ischemic tissues," Cell Biochemistry and Biophysics, vol. 62, no. 3, pp. 409414, 2012.

[127] M. W. Maijenburg, C. Gilissen, S. M. Melief et al., "Nuclear receptors Nur77 and Nurr1 modulate mesenchymal stromal cell migration," Stem Cells and Development, vol. 21, no. 2, pp. 228-238, 2012.

[128] F. Belema-Bedada, S. Uchida, A. Martire, S. Kostin, and T. Braun, "Efficient homing of multipotent adult mesenchymal stem cells depends on FROUNT-mediated clustering of CCR2,” Cell Stem Cell, vol. 2, no. 6, pp. 566-575, 2008.

[129] S. Kumar and S. Ponnazhagan, "Bone homing of mesenchymal stem cells by ectopic $\alpha 4$ integrin expression," FASEB Journal, vol. 21, no. 14, pp. 3917-3927, 2007.

[130] Y. Liu, L. Wang, T. Kikuiri et al., "Mesenchymal stem cellbased tissue regeneration is governed by recipient $\mathrm{T}$ lymphocytes via IFN- $\gamma$ and TNF- $\alpha$," Nature Medicine, vol. 17, no. 12, pp. 1594-1601, 2011.

[131] O. M. Alvarez, P. M. Mertz, R. V. Smerbeck, and W. H. Eaglstein, "The healing of superficial skin wounds is stimulated by external electrical current," Journal of Investigative Dermatology, vol. 81, no. 2, pp. 144-148, 1983.

[132] G. J. Bourguignon and L. Y. Bourguignon, "Electric stimulation of protein and DNA synthesis in human fibroblasts," FASEB Journal, vol. 1, no. 5, pp. 398-402, 1987.

[133] S. E. Gardner, R. A. Frantz, and F. L. Schmidt, "Effect of electrical stimulation on chronic wound healing: a metaanalysis," Wound Repair and Regeneration, vol. 7, no. 6, pp. 495-503, 1999.

[134] R. B. Borgens, "Stimulation of neuronal regeneration and development by steady electrical fields," Advances in Neurology, vol. 47, pp. 547-564, 1988.

[135] S. Shapiro, R. Borgens, R. Pascuzzi et al., "Oscillating field stimulation for complete spinal cord injury in humans: a phase 1 trial," Journal of Neurosurgery, vol. 2, no. 1, pp. 3-10, 2005.

[136] D. Perry, J. Colthurst, P. Giddings, D. A. McGrouther, J. Morris, and A. Bayat, "Treatment of symptomatic abnormal skin scars with electrical stimulation," Journal of Wound Care, vol. 19, no. 10, pp. 447-453, 2010.

[137] Z. Zhao, C. Watt, A. Karystinou et al., "Directed migration of human bone marrow mesenchymal stem cells in a physiological direct current electric field," European Cells \& Materials, vol. 22, pp. 344-358, 2011.

[138] W. Wu, H. Zhao, B. Xie et al., "Implanted spike wave electric stimulation promotes survival of the bone marrow mesenchymal stem cells and functional recovery in the spinal cord injured rats," Neuroscience Letters, vol. 491, no. 1, pp. 73-78, 2011. 

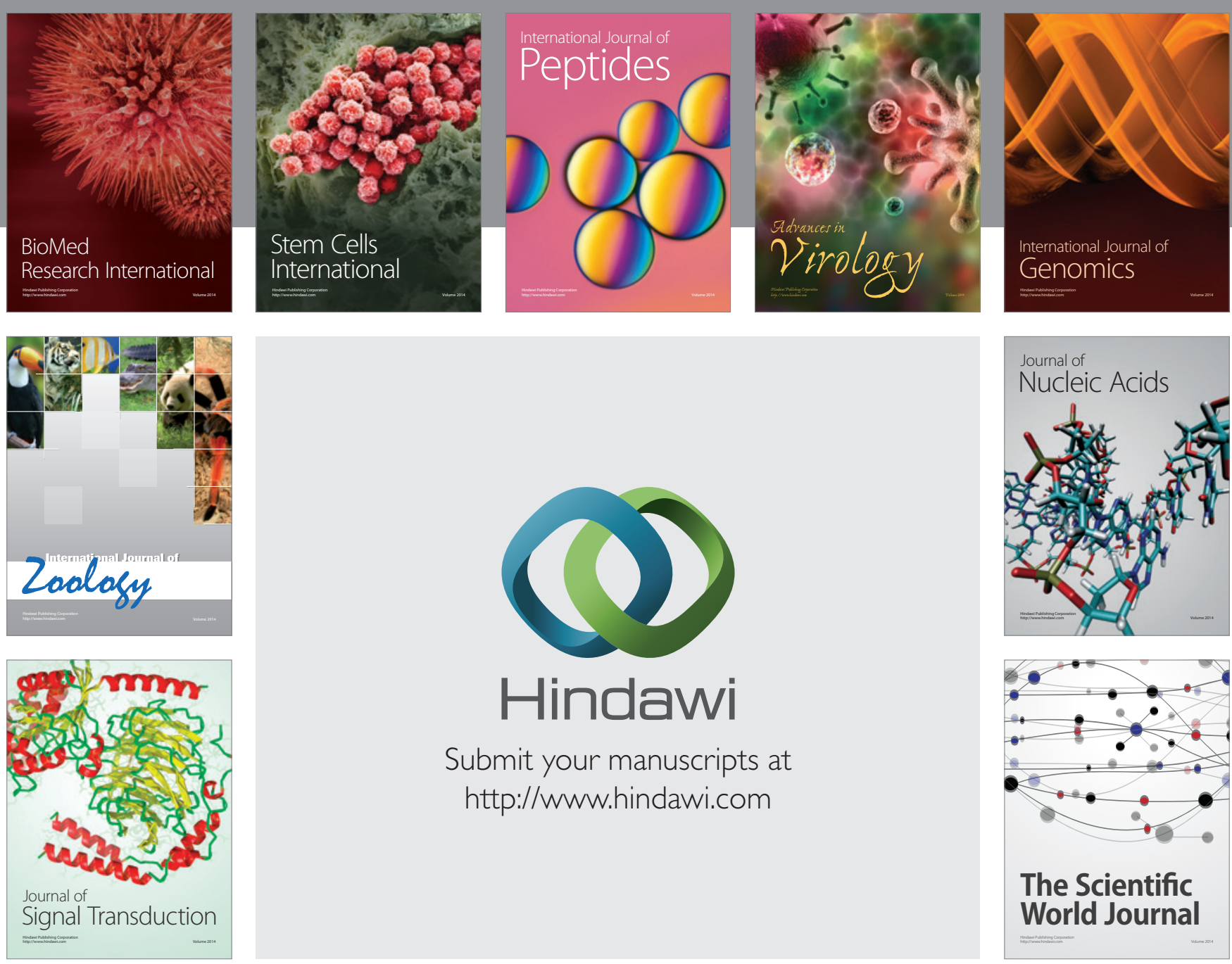

Submit your manuscripts at

http://www.hindawi.com
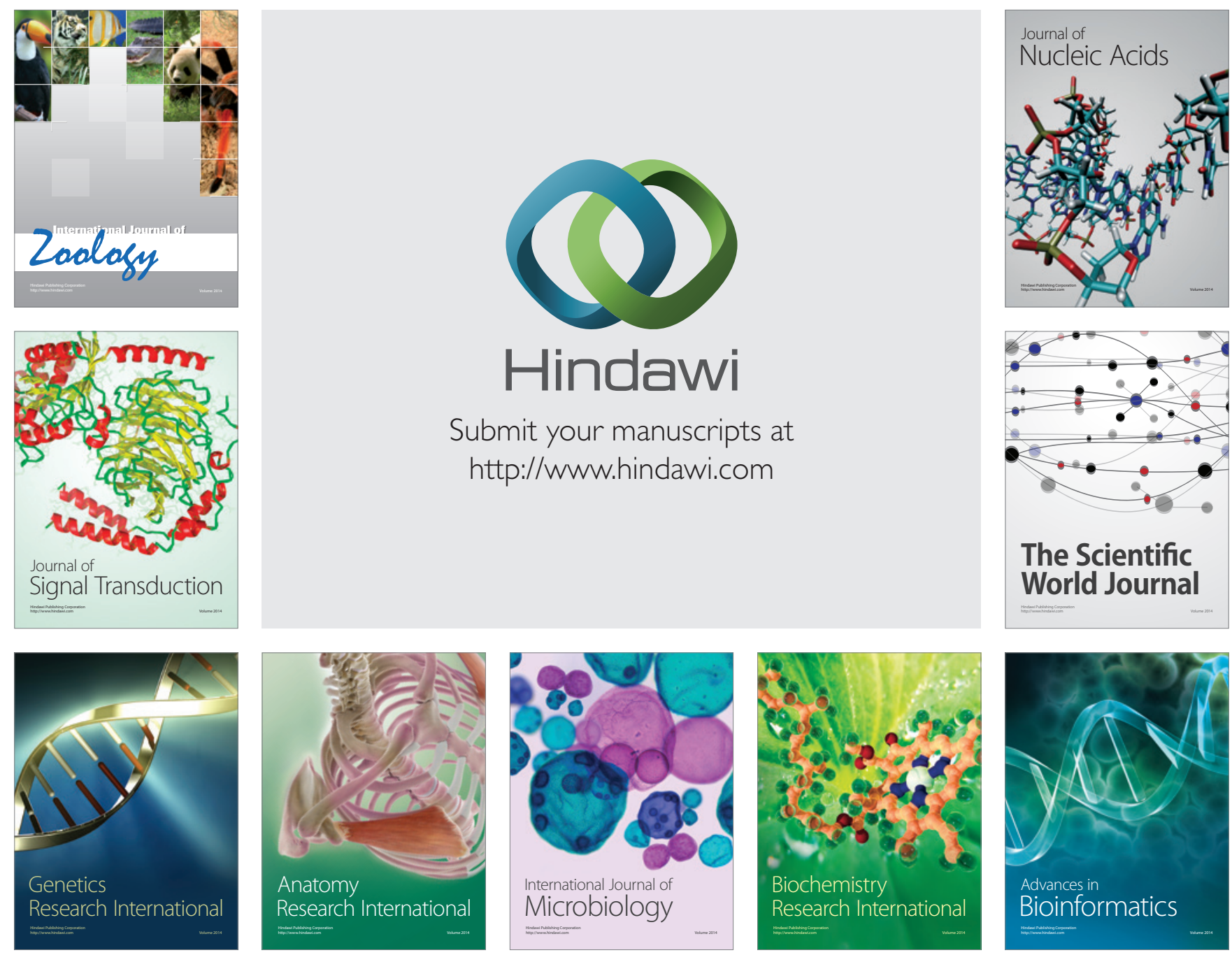

The Scientific World Journal
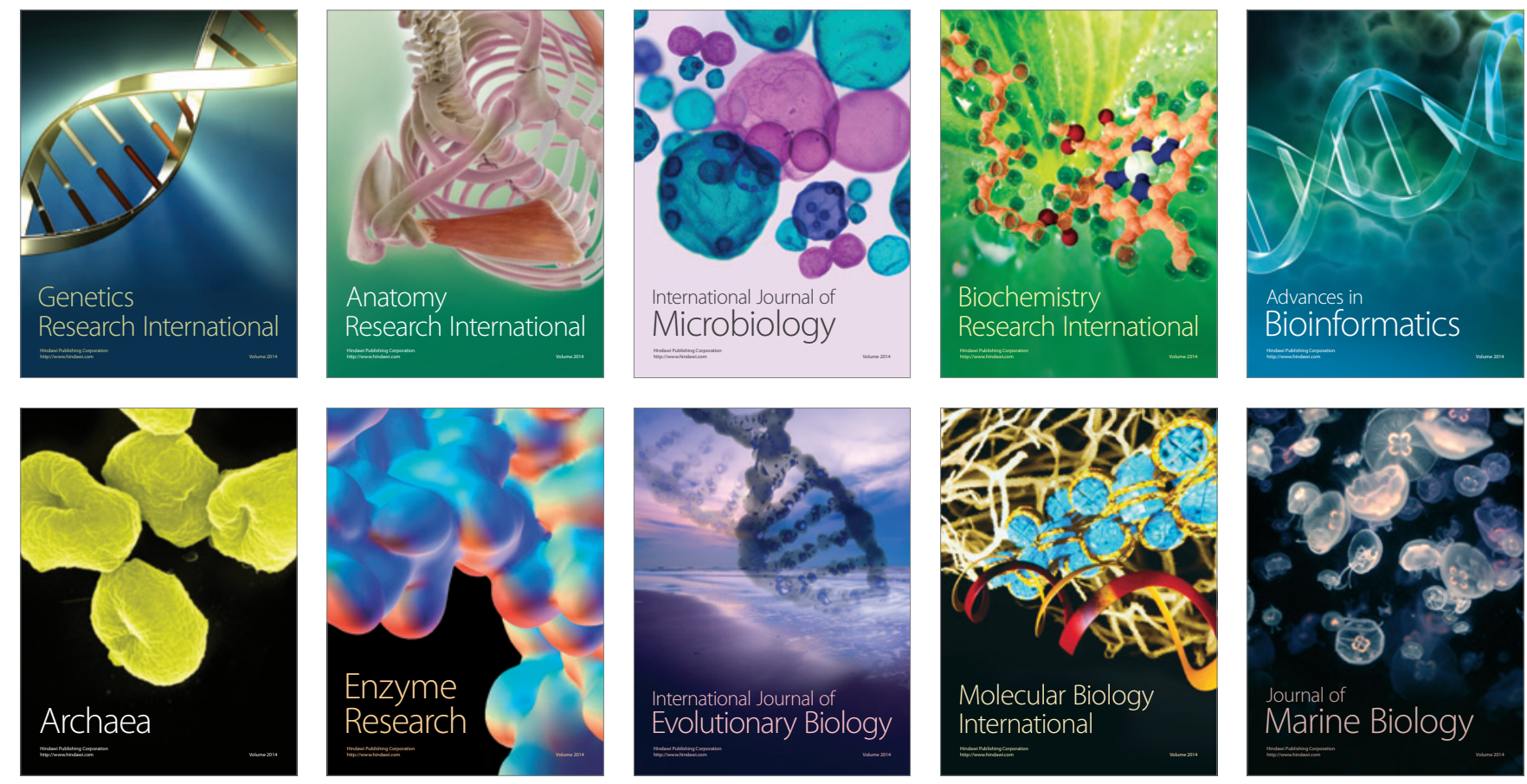